\title{
Laccase and Manganese Peroxidase (MnP) Activities in the White-Rot Fungus Trametes hirsuta in Response to Aromatic Compounds
}

\author{
Isa Nuryana $^{1 *}$, Zidny Ilmiah $^{1}$, Ade Andriani $^{1}$, and Yopi $^{2}$ \\ ${ }^{1}$ Research Center for Biotechnology, Indonesian Institute of Sciences \\ Jln. Raya Bogor Km 46, Cibinong, Bogor 16911 \\ ${ }^{2}$ National Standardization Agency of Indonesia \\ Jln. MH Thamrin No. 8, Kebon Sirih, Jakarta Pusat 10340
}

\begin{abstract}
The current interest in exploring white-rot fungi has been concentrated in increasing their ligninolityc enzyme production such as laccase and manganese peroxidase $(\mathrm{MnP})$ due to the great value in industrial application. The presence of appropiate inducers can enhance the enzyme production. Hence, the aim of the study was to investigate the activity of laccase and $\mathrm{MnP}$ in response to various aromatic compounds. The fungus Trametes hirsuta was cultured in Glucose Yeast Peptone (GYP) broth ( $\mathrm{pH} 5.0$ ) with the addition of $0.5 \%$ of sorghum biomass as substrate. The cultures were then incubated on rotary shaker at $150 \mathrm{rpm}$ at $27^{\circ} \mathrm{C}$. The 7 -day-old cultures were then supplemented with different aromatic compounds, namely caffeic acid, gallic acid, syringic acid, trans-cinnamic acid, vanillin, and veratryl alcohol. Our results demonstrated that veratryl alcohol, gallic acid and vanillin gave an inductive effect on the value of laccase and MnP activities, with vanillin showing the highest induction. On the contrary, the level of laccase and MnP activities remained low in the presence of aromatic compound such as syringic acid, trans-cinnamic acid and caffeic acid. To conclude, our study reveals that aromatic compounds can be potential as inducers and may contribute to the improvement of laccase and MnP productivity by $T$. hirsuta.
\end{abstract}

Keywords: Aromatic compounds, Glucose Yeast Peptone medium, Laccase, Manganese peroxidase, Trametes hirsuta

*Corresponding author:

Cibinong Science Center, Jl. Raya Bogor Km. 46, Cibinong 16911, Indonesia

Tel. +62-21-8754587, Fax. +62-21-87754588

E-mail. isa.nuryana@gmail.com

\section{Introduction}

White-rot fungi, which are mostly basidiomycetes, play an important role in the forest ecosystem (Martinez et al., 2005). Due to their ability to decompose the plant cell wall components, degrade wood-based biomass and catalyze organic pollutants, white-rot fungi have been extensively used in agricultural, environmental, and industrial application (Pointing, 2001; Asgher et al., 2008). The degradation process is related to their capability of synthesizing various extracellular ligninolytic enzymes such as manganese and lignin peroxidase, cellulase and laccase (Bugg et al., 2011). These enzymes are responsible in decomposing lignocellulose including lignin, cellulose, hemicellulose, and converting into low molecular weight compounds that can be assimilated by fungi for nutrient intake (Songulashvili et al., 2007).
As a ligninolytic enzyme, laccase (E.C. 1.10.3.2) belongs to a group of coppercontaining polyphenol oxidases which is able to catalyze the four-electron reduction of $\mathrm{O}_{2}$ to $\mathrm{H}_{2} \mathrm{O}$ coupled with the oxidation of phenolic compounds (Baldrian, 2006). Another ligninolytic enzyme, Manganese peroxidase (MnP) (E.C. 1.11.1.13) belongs to the family of oxidureductases, which can catalyze the $\mathrm{H}_{2} \mathrm{O}_{2}$ - dependent oxidation of lignin derivates based polymer (Zhou et al., 2013; Qin et al., 2014). The MnP is a specific enzyme that can oxidize $\mathrm{Mn}^{2+}$ to $\mathrm{Mn}^{3+}$ (Xu et al., 2017). Despite the application in agriculture, both laccase and MnP have great potential to protect the environment by degrading some recalcitrant organic pollutants such as chlorophenols, textile dye effluents, aromatic hydrocarbons, which are harmful to human health (Shraddha et al., 2011). 
The great value of extracellular white-rot fungi enzymes in biotechnological applications have leaded several studies in obtaining and developing a large amount of ligninolytic enzyme production in a low-cost process (Elisashvili et al., 2009). One of the most effective and efficient way to enhance the enzyme production is the supplementation of the nutrient medium with compatible inducers (Revankar \& Lele, 2006). Earlier studies have suggested that laccase and MnP production can be stimulated by the presence of external factor such as plant raw materials, aromatic compounds, metal ions, nutrient carbon and nitrogen (Galhaup \& Haltrich, 2001; Soden \& Dobson, 2001).

In the present study, we utilized the plant raw materials from sorghum biomass as substrate with the supplementation of various aromatic compounds as inducers. The aim of the study was to investigate the synergistic effect of both substrate and inducers on laccase and $\mathrm{MnP}$ production.

\section{Materials and Methods}

\section{Fungal Strain and Medium Preparation}

The white-rot fungus used was Trametes hirsuta isolated from Botanical Garden of Cibinong Science Center, West Java, Indonesia. It was then preserved at Laboratory of Biocatalyst and Fermentation, Research Center for Biotechnology, LIPI. The fungal strain was recultured on Malt Extract Agar (MEA) medium. After 7 days of incubation at room temperature, the strain was prepared for the cultures and enzyme production.

\section{Culture Conditions}

The basal medium used for cultures was Glucose Yeast Peptone (GYP) broth contained per $\mathrm{L}$ of $20 \mathrm{~g}$ glucose, $5 \mathrm{~g}$ yeast extract, $5 \mathrm{~g}$ peptone, and $2 \mathrm{~g} \mathrm{MgSO}_{4} \cdot 7 \mathrm{H}_{2} \mathrm{O}$. Amount of $0.5 \%$ of sorghum biomass was added to GYP broth as substrate for the enzyme production. The initial $\mathrm{pH}$ medium was adjusted to 5.0 by the addition of $\mathrm{HCl}$ solution prior to sterilization. Three plugs of outer fungal colony growing on MEA were inoculated into $100 \mathrm{ml}$ of GYP broth. The culture was then incubated on rotary shaker at $150 \mathrm{rpm}$ at temperature of $27^{\circ} \mathrm{C}$. After 7 days of cultivation, various aromatic compounds (caffeic acid, gallic acid, syringic acid, veratryl alcohol, trans-cinnamic acid, and vanillin) were added as inducers into the fungal cultures at final concentration of 0.5 $\mathrm{mM}$ for each compound. After adding the inducers, the cultures of $T$. hirsuta were cultivated at temperature of $27^{\circ} \mathrm{C}$ with shaking continously at $150 \mathrm{rpm}$. At interval time of sampling, a $10 \mathrm{ml}$ of cultures in flasks was withdrawn as a sampel and separated by centrifugation at $10,000 \mathrm{~g}$ for $10 \mathrm{~min}$ at $4^{\circ} \mathrm{C}$. The pellet was analyzed for mycelial dry weight and clear supernatant was measured for the enzyme activity.

\section{Laccase and MnP Activities Assay}

Laccase and MnP activities were determined according to the method as described by Andriani \& Tachibana (2016). Laccase activity was measured at wavelength $525 \mathrm{~nm}$ with the addition of $750 \mu \mathrm{l}$ of sodium acetate buffer $(\mathrm{pH}$ 5.3) and $100 \mu \mathrm{l}$ of syringaldazine as the substrate into $900 \mu \mathrm{l}$ of clear supernatant. Meanwhile, MnP activity was measured at wavelength $470 \mathrm{~nm}$ with the addition of the reaction mixture containing $125 \mu \mathrm{l}$ of $20 \mathrm{mM}$ 2,6-dimethoxyphenol as the substrate, $1.75 \mathrm{ml}$ of $50 \mathrm{mM}$ malonate buffer ( $\mathrm{pH} 4.5$ ), $125 \mu \mathrm{l}$ of $20 \mathrm{mM} \mathrm{MnSO}{ }_{4}$ solution, and $300 \mu \mathrm{l}$ of $2 \mathrm{mM}$ $\mathrm{H}_{2} \mathrm{O}_{2}$ into $1 \mathrm{ml}$ of crude enzyme-containing supernatant. Samples was examined using UVVis spectrophotometer, the increase of absorbance was monitored per $10 \mathrm{sec}$ within 1 min. One unit of enzyme activity was defined as the amount of enzyme required to oxidize 1 $\mu \mathrm{mol}$ of substrate per min.

\section{Determination of Mycelial Dry Weight}

Determination of mycelial dry weight was conducted with harvesting the fungal cultures and separating by centrifugation. The mycelialcontained pellets were then dried at $80^{\circ} \mathrm{C}$ in oven. After reaching to a constant weight, mycelial dry weight was examined.

\section{Determination of Sugars Using HPLC}

Xylose and residual glucose were determined using Shimadzu HPLC System equipped with Aminex column and refractive index detector (RID). The mobile phase used was $5.0 \mathrm{mM} / \mathrm{L} \mathrm{H}_{2} \mathrm{SO}_{4}$ in ultrapure water (HPLC grade) at flow rate of $0.6 \mathrm{ml}$ per min. A volume of $10 \mu \mathrm{l}$ of respective sample was injected with a run time of $40 \mathrm{~min}$. Sugar standards were dilluted in ultrapure water and prepared at different concentrations. The quantification of 
sugars were measured using a regression equation from serial concentration of standards.

\section{Results}

Optimum Conditions for the Cultures, Fungal Growth and Enzyme Production

Optimization of fungal culture conditions was carried out in order to obtain the optimum conditions of fungal growth and enzyme production. In this experiment, $T$. hirsuta was grown in GYP broth with or without substrate and shaking treatment to examine the enzyme production.

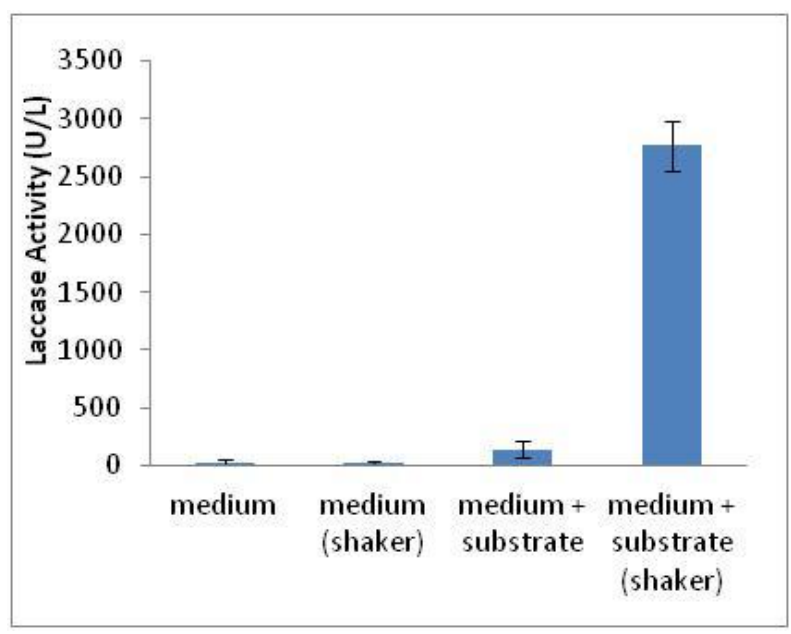

Figure 1. Laccase activity in different culture conditions

The laccase activity reached higher level at shaking than stationary cultivation (Figure 1). The best condition for laccase production was fungal strain cultivated in GYP medium with the addition of $0.5 \%$ sorghum biomass as the substrate on a rotary shaker at $150 \mathrm{rpm}$ and $27^{\circ} \mathrm{C}$. Laccase activity achieved the highest degree at 2,765 U/L. The fungus was most likely to make contacts with the substrate in shaking condition so that it could stimulate the fungus to produce the highest level of enzyme production.

As depicted in Figure 1, the fungal strain had no ability to produce the laccase while growing in the GYP medium without sorghum biomass. The strain showed the increase of the cell growth day by day without any capability to produce laccase (data not shown). The glucose in the medium could only trigger the cell growth but the addition of sorghum biomass had successfully improved the enzyme production.

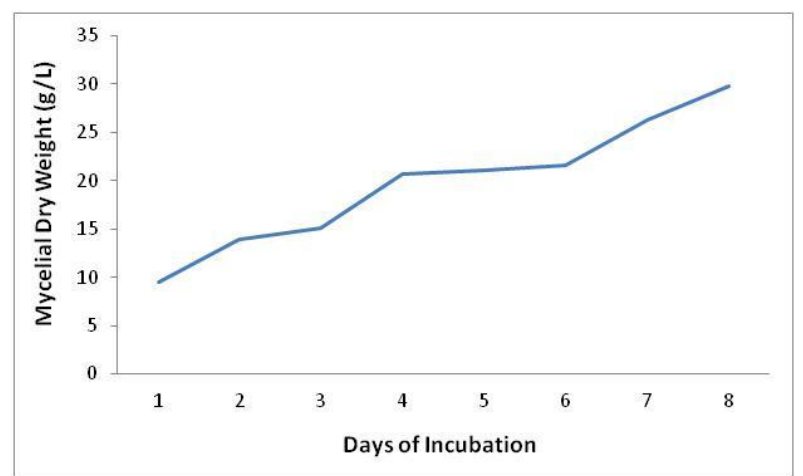

Figure 2. Mycelial dry weight during days of incubation

We also observed the growth of T. hirsuta by measuring its mycelial dry weight within 7 days of incubation. The growth of filamentous microbes can be generally assessed using dry weight determination. We could understand that during the incubation period, the most active growth of the fungus occured between sixth and seventh day. The mycelial dry weight increased from $21.55 \mathrm{~g} / \mathrm{L}$ at sixth day to $26.35 \mathrm{~g} / \mathrm{L}$ at seventh day (Figure 2).

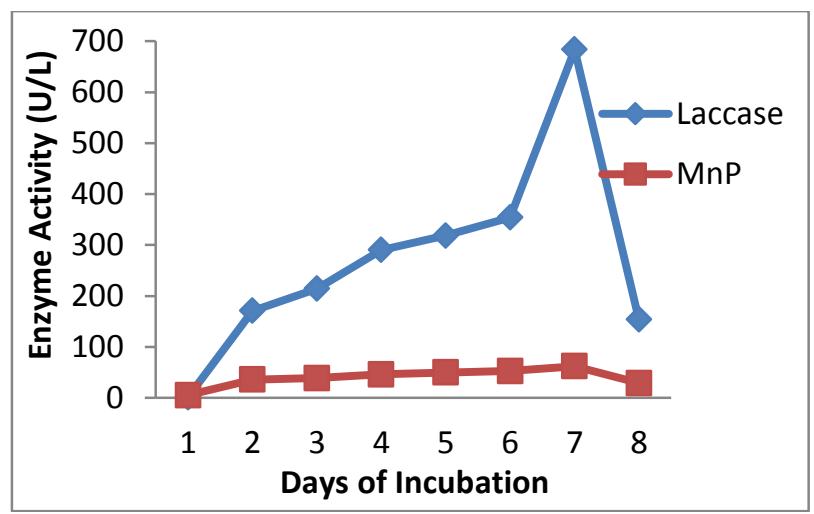

Figure 3. Enzyme activity during days of incubation

Determination of enzyme activity during the incubation period was necesary to obtain the optimum time of the cultures to be treated by aromatic compounds. The data shown in Figure 2 and 3 respectively demonstrated that the highest level of the mycelial biomass growth and enzyme production was attained on day 7 . Hence, day 7 was the best and appropiate time for the culture to be stimulated by different aromatic compounds.

\section{Effect of Aromatic Compounds on Laccase and MnP Production}

To study the response of laccase and $\mathrm{MnP}$ production to various inducers, we 
supplemented $0.5 \mathrm{mM}$ of each aromatic compound into the 7-day-old culture of $T$. hirsuta. As depicted in Figure 4, veratryl alcohol, gallic acid and vanillin used in this study gave an inductive effect on the value of laccase activity, with vanillin showing the highest induction. On the contrary, other aromatic compounds such as syringic acid, trans-cinnamic acid and caffeic acid had no inductive effect on laccase activity. Their value was almost similar and close to the value of the control (GYP medium and sustrate-added GYP medium).

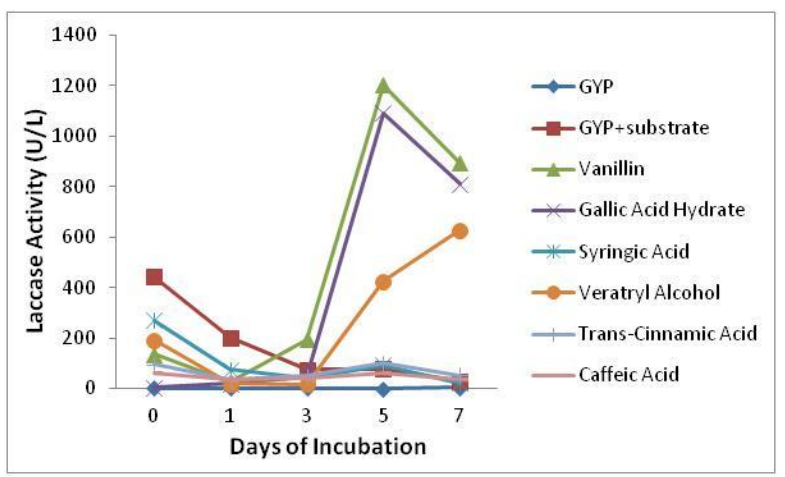

Figure 4. Laccase activity after the addition of aromatic compounds

Vanillin and gallic acid stimulated 6-fold laccase production on day 3 to day 5 and drastically decrease on day 7. Furthermore, veratryl alcohol also induced laccase activity on day 3 and continued increasing on day 7 .

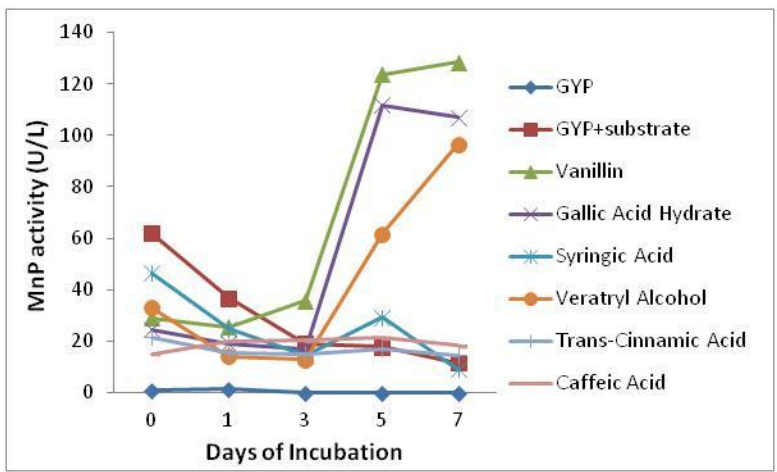

Figure 5. Manganese peroxidase (MnP) activity after the addition of aromatic compounds

Meanwhile, the similar pattern was also found in this study. A significant increase in $\mathrm{MnP}$ activity was observed when the culture of T. hirsuta was stimulated by veratryl alcohol, gallic acid and vanillin whereas MnP activity remained low throughout the incubation in the presence of inducers such as syringic acid, trans-cinnamic acid and caffeic acid (Figure 5). The aromatic compounds was detected to give the inductive effect on $\mathrm{MnP}$ activity after 3 days of incubation and remained increasing on day 7 .

\section{Effect of Aromatic Compounds on Residual Glucose and Xylose Content}

The presence of aromatic compounds in the culture medium has also affected to the use of glucose and the yield of xylose. The decrease of glucose could be found after the addition of aromatic compounds with a range $11 \mathrm{mg} / \mathrm{L}$ to $218 \mathrm{mg} / \mathrm{L}$. On other hand, the medium without the supplementation of substrate and inducers, the amount of residual glucose remained high $(7,180 \mathrm{mg} / \mathrm{L})$. In the absence of substrate, the capability of producing extracellular ligninolytic enzymes was very low as well as the glucose consumption. Xylose, which is derived from hemicellulose, was detected low level in this study. Makela et al. (2018) reported that the resulting sugar such as D-xylose could be taken up by the fungal cell and coverted to energy or biomolecul precursors.

Table 1. Residual glucose and xylose product after 7 days of incubation

\begin{tabular}{lcc}
\hline \multicolumn{1}{c}{ Compounds } & $\begin{array}{c}\text { Residual glucose } \\
(\mathrm{mg} / \mathrm{L})\end{array}$ & $\begin{array}{c}\text { Xylose } \\
(\mathrm{mg} / \mathrm{L})\end{array}$ \\
\hline Medium (control) & 7,180 & $\mathrm{n} / \mathrm{a}$ \\
Medium + substrate & 150 & 28 \\
(control) & 190 & 20 \\
Caffeic acid & 20 & 52 \\
Gallic acid & 218 & 41 \\
Syringic acid & 92 & 43 \\
Trans-cinnamic acid & 53 & 174 \\
Vanillin & 11 & 123 \\
Veratryl alcohol & &
\end{tabular}

\section{Discussion}

In this work, we used a white-rot fungi strain Trametes hirsuta to study its activity of laccase and $\mathrm{MnP}$ under the induction. The fungus was isolated from Botanical Garden of Cibinong Science Center, West Java, Indonesia and known to have great potential in producing several ligninolytic enzymes. It was also able to synthesize the high level of laccase and $\mathrm{MnP}$ in the sorghum biomass-containing medium under shaking condition. Elisashvili et al. (2008, 
2009) have reported that the utilization of plant materials and biomass could produce the high yield of enzymes without supplementation of specific inducers in the culture medium. The major components of plant cell wall is lignocellulose, which can be a good substrate to stimulate the enzymes production.

Although the presence of sorghum biomass in the medium could provide sufficient condition to produce the high level of enzymes, the supplementation of several aromatic compounds could also induce the enhancement of enzymes production. We have examined six aromatic compounds to study their inductive effect on laccase and $\mathrm{MnP}$ activities. There was differences in enzyme activities in response to each aromatic compound. The highest level of enzyme activity was attained in response to vanillin, followed by gallic acid and veratryl alcohol. Furthermore, the enzyme synthesis could be gradually increased on day 3 to day 7 by the supplementation medium with vanillin. Our results comply with the finding of earlier studies that have reported the highest induction on laccase production due to the addition of vanillin (Tussel et al., 2015).

On the contrary, the enzymes had low activities in the presence of syringic acid, transcinnamic acid and caffeic acid. The level of activities were similar to the control medium which means that the addition of aromatic compounds had no effect to enzymes activities. A previous report revealed that laccase production in the Trametes velutina could be induced and enhanced by syringic acid and cinnamic acid (Yang et al., 2013). The disparity in findings could be due to the differences in concentration of aromatic compounds used, the differences in fungal strain used and the various research conditions such as medium or equipments.

Generally, aromatic compounds, which are structurally related to lignin, play an important role on ligninolytic enzymes production. Therefore, one of the main factors that can determine the high induction is the chemical structure (Terron et al., 2004). Moreover, that compounds with different substituted groups can also induce the synthesis of laccase isozymes (Xiao et al., 2004). The enhanced laccase synthesis may have function as a defense mechanism against chemical stress (Elisashvili et al., 2010).

In conclusion, the combination of GYP medium and sorghum biomass with the supplementation of aromatic compounds in the culture is potential to give synergistic effect on laccase production. Our study has suggested that laccase and $\mathrm{MnP}$ production can be improved by aromatic compounds. Further studies should be performed in order to enhance laccase and MnP production to higher level through optimizing conditions.

\section{Acknowledgements}

The authors would like to thank to DIPA Prioritas Nasional Energi of Research Center for Biotechnology LIPI fiscal year 2019 for the financial support to this work.

\section{References}

Andriani, A. \& Tachibana, S. (2016). Lignocellulosic materials as solid support agents for Bjerkandera adusta SM46 to enhance polycyclic aromatic hydrocarbon degradation on sea sand and sea water media. Biocatalyst and Agricultural Biotechnolog, 8: 310-320.

Asgher, M., Bhatti, H. N., Ashraf, M., \& Legge, R. L. (2008). Recent developments in biodegradation of industrial pollutants by white rot fungi and their enzyme system. Biodegradation, 19: 771-783.

Baldrian, P. (2006). Fungal laccases-occurrence and properties. FEMS Microbiol Rev, 30: 215-242.

Bugg, T. D. H., Ahmad, M., Hardiman, E. M., \& Rahmanpour, R. (2011). Pathways for degradation of lignin in bacteria and fungi. Nat Prod Rep., 28: 1883-96. https://doi.org/10.1039 /c1np00042jPMID:21918777.

Elisashvili, V., Kachlishvili, E., \& Penninckx, M. (2008). EVect of growth substrate, method of fermentation, and nitrogen source on lignocellulose-degrading enzymes production by white-rot basidiomycetes. $J$ Ind Microbiol Biotechnol, 35: 1531-1538.

Elisashvili V. \& Kachlishvili, E. (2009). Physiological regulation of laccase and manganese peroxidase production by white-rot Basidiomycetes. Journal of Biotechnology, 144: 37-42.

Elisashvili, V., Kachlishvili, E., Khardziani, T., \& Agathos, S. N. (2010). Effect of aromatic compounds on the production of laccase and manganese peroxidase by white-rot basidiomycetes. J Ind Microbiol Biotechnol, 37: 1091-1096.

Galhaup C. \& Haltrich, D. (2001). Enhanced formation of laccase activity by the white-rot 
fungus Trametes pubescens in the presence of copper. Appl Microbiol Biotechnol, 56: 225-232.

Makela, M. R., Pontes, M. V. A., Uffink, D. V. R., Peng, M., \& Vries, R. P. D. (2018). The fungus Aspergillus niger consumes sugars in a sequential manner that is not mediated by the carbon catabolite repressor CreA. Scientific Reports, 8: 6655.

Martı'nez, A. T., Speranza, M., Ruiz-Dueñas, F. J., Ferreira, P., Camarero, S., \& Guille'n, F. (2005). Biodegradation of lignocellulosics: microbial, chemical, and enzymatic aspects of the fungal attack of lignin. Int Microbiol., 8: 195-204. Available:http://www.ncbi.nlm.nih.gov/pubmed /16200498 PMID: 16200498

Pointing, S. B. (2001). Feasibility of bioremediation by white-rot fungi. Appl Microbiol Biotechnol, 57: 20-33.

Qin, X., Zhang, J., Zhang, X., \& Yang, Y. (2014). Induction, purification, and characterization of a novel manganese peroxidase from Irpex lacteus CD2 and its application in the decolorization of different types of dye. PloS One.

Revankar, M. S. \& Lele, S. S. (2006). Enhanced production of laccase using a new isolate of white-rot fungus WR-1. Process Biochem, 41: 581-588.

Shraddha, Shekher, R., Sehgal, S., Kamthania, M., \& Kumar, A. (2011). Laccase: Microbial sources, production, purification, and potential biotechnological applications. Enzyme Research. doi:10.4061/2011/217861.

Soden, D. M. \& Dobson, A. D. W. (2001). Differential regulation of laccase gene expression in Pleurotus sajor-caju. Microbiology, 147: 1755-1763.

Songulashvili, G., Elisashvili, V., Wasser, S. P., Nevo, E., \& Hadar, Y. (2007). Basidiomycetes laccase and manganese peroxidase activity in submerged fermentation of food industry wastes. Enzyme and Microbial Technology, 41: 57-61.

Terrón, M. C., González, T., Carbajo, J. M., Yagüe, S., Arana-Cuenca, A., Téllez, A., Dobson, A. D. W., \& González, A. E. (2014). Structural closerelated aromatic compounds have different effects on laccase activity and lcc gene expression in the ligninolytic fungus Trametes sp. I-62. Fungal Genet. Biol., 41: 954-962.

Tussel, R. T., Brito, D. P., Calzada, C. T., Velazquez, A. C.., Gaviria, L. A., Villacis, R. C., \& Pereira, S. S. (2015). Laccase gene expression and vinasse biodegradation by Trametes hirsuta strain Bm-2. Molecules, 20: 15147-15157.

Xiao, Y. Z., Chen, Q., Hang, J., Shi, Y. Y., Wu, J., Hong, Y. Z., \& Wang, Y. P. (2004). Selective induction, purification and characterization of a laccase isozyme from the basidiomycete Trametes sp. AH28-2. Mycologia, 96: 26-35.

Xu, H., Guo, M. Y., Gao, Y. H., Bai, X. H., \& Zhou, X. W. (2017). Expression and characteristics of manganese peroxidase from Ganoderma lucidum in Pichia pastoris and its application in the degradation of four dyes and phenol. $B M C$ Biotechnology, 17: 19

Yang, T., Wei, F., Zhuo, R., Fan, F., Liu, H., Zhang, C., Ma, L., Jiang, M., \& Zhang, X. (2013). Enhancing the laccase production and laccase gene expression in the white-rot fungus Trametes velutina 5930 with great potential for biotechnological applications by different metal ions and aromatic compounds. PloS One, 8.

Zhou, X. W., Cong, W. R., Su, K. Q., Zhang, Y. M. (2013). Ligninolytic enzymes from Ganoderma spp: Current status and potential applications. Crit Rev Microbiol., 39: 416-426. 